\title{
Nucleophilic Addition of Reactive Dyes on Amidoximated Acrylic Fabrics
}

\author{
Reda M. El-Shishtawy, ${ }^{1,2}$ Manal M. El-Zawahry, ${ }^{2}$ \\ Fatma Abdelghaffar, ${ }^{2}$ and Nahed S. E. Ahmed ${ }^{2}$ \\ ${ }^{1}$ Chemistry Department, Faculty of Science, King Abdulaziz University, P.O. Box 80203, Jeddah 21589, Saudi Arabia \\ ${ }^{2}$ Dyeing, Printing and Textile Auxiliaries Department, Textile Research Division, National Research Center, Dokki, Giza 12622, Egypt
}

Correspondence should be addressed to Reda M. El-Shishtawy; elshishtawy@hotmail.com

Received 10 June 2014; Revised 20 July 2014; Accepted 22 July 2014; Published 28 August 2014

Academic Editor: Run-Cang Sun

Copyright (C) 2014 Reda M. El-Shishtawy et al. This is an open access article distributed under the Creative Commons Attribution License, which permits unrestricted use, distribution, and reproduction in any medium, provided the original work is properly cited.

\begin{abstract}
Seven reactive dyes judiciously selected based on chemical structures and fixation mechanisms were applied at $2 \%$ owf of shade on amidoximated acrylic fabrics. Amidoximated acrylic fabric has been obtained by a viable amidoximation process. The dyeability of these fabrics was evaluated with respect to the dye exhaustion, fixation, and colour strength under different conditions of temperature and dyeing time. Nucleophilic addition type reactive dyes show higher colour data compared to nucleophilic substitution ones. FTIR studies further implicate the binding of reactive dyes on these fabrics. A tentative mechanism is proposed to rationalize the high fixation yield obtained using nucleophilic addition type reactive dyes. Also, the levelling and fastness properties were evaluated for all dyes used. Excellent to good fastness and levelling properties were obtained for all samples irrespective of the dye used. The result of investigation offers a new method for a viable reactive dyeing of amidoximated acrylic fabrics.
\end{abstract}

\section{Introduction}

Acrylic fabric is a wool-like fabric with outstanding chemical and physical properties such as lightweight, soft, high strength, and good abrasion and insect resistance. These characteristics have led to its application in textile industries as a less expensive alternative to wool [1]. Acrylic fabric, which is a synthetic polymer made from a copolymer of acrylonitrile containing 1-15 mass \% of several vinyl comonomers containing carboxylate or sulphonate groups, is conventionally dyed with cationic dyes [2,3]. As acrylic fabrics are widely used in textile blends with natural fabrics such as wool and cotton, thus the viability of using different dyes for the colouration of acrylic fabrics would have a positive impact on textile industries. In this regard, reactive dyes and anionic dyes such as acid dyes are not usually used for acrylic colouration as these dyes suffer from being not substantive for the fabrics as a result of the repulsive effects that occur between the anionic groups present in the fabrics and those present in the dye molecules. For this purpose and in the interest of making acrylic fabrics less hydrophobic, anionic dyeable, a facile, safe, and efficient pretreatment method in which a partial conversion of nitrile groups present in the fabrics into amidoxime groups has been reported [4]. The amidoxime groups as the active dye sites have proven effectiveness in increasing the substantivity of acrylic fabrics toward anionic dyes at an acidic $\mathrm{pH}[4-7]$.

Amidoxime is effective $\alpha$-nucleophile and its $\mathrm{O}$-nucleophilic characteristics revealed a unique capability of reacting with an acylating agent in the basic, neutral, and acidic media $[8,9]$. Additionally, an unusually fast nucleophilic addition of amidoximes to acetylene has been reported [10]. This outstanding nucleophilicity of amidoxime group prompted us to reveal the mechanism of reactive dye fixation on amidoximated acrylic fabrics. Reactive dye fixation proceeds by two main mechanisms; nucleophilic addition and nucleophilic substitution and this mechanism depend on the dye type and the textile substrate [11, 12].

In continuation of our interest in anionic colouration of acrylic fabrics and stemmed by the results of one-bath 
reactive dyeing of amidoximated wool/acrylics in which a remarkable high reactive dye fixation value was obtained at acidic $\mathrm{pH}$ [7], it was of interest to investigate the dyeing characteristics of amidoximated acrylic fabrics using different types of reactive dyes. The purpose of this work was to explore the viability of reactive dye fixation on amidoximated acrylic fabrics for the first time and to determine which type of fabric reactive dyes is suitable for such fabrics (i.e., nucleophilic addition or nucleophilic substitution type reactive dyes). Pretreatment of acrylic fabrics and its impact on tensile strength is presented. The pretreated fabrics are then subjected for colouration with different reactive dyes under different conditions and the fastness properties of the dyed samples are then evaluated.

\section{Experimental}

\subsection{Materials}

2.1.1. Acrylic Fabrics. The acrylic fabrics used in this study was a $1 / 1$ woven acrylic $(40.65 \times 40.65$ threads/inch for both weft and warp) with $0.36 \mathrm{~g} / \mathrm{cm}^{3}$ density, supplied by Misr ElMehalla Co., Egypt. The fabric was soaped with $2 \mathrm{~g} / \mathrm{L}$ nonionic detergent (Hostapal CV, from Clariant-Egypt) at $60^{\circ} \mathrm{C}$ for $30 \mathrm{~min}$, thoroughly rinsed and air dried.

2.1.2. Dyestuffs and Chemicals. The dyes used in this work were CI Reactive Blue 19 (RB19), CI Reactive Orange 16 (RO16), CI Reactive Violet 5 (RV5), CI Reactive Red 84 (RR84), CI Reactive Blue 171 (RB171), CI Reactive Red 4 (RR4), and CI Reactive Red 195 (RR195). These dyes were kindly supplied by Ciba-Egypt and were used as received. All other chemical reagents were of laboratory grade.

\subsection{Pretreatment and Dyeing}

2.2.1. Pretreatment. Following our previously described method [4], a known mass of acrylic fabric was pretreated with hydroxylamine hydrochloride $(0-14 \mathrm{~g} / \mathrm{L})$ using aqueous solutions of ammonium acetate $(20 \mathrm{~g} / \mathrm{L})$ at a liquor-to-goods ratio of $50: 1$ at $85^{\circ} \mathrm{C}$ for $60 \mathrm{~min}$. The pretreated samples were thoroughly rinsed with water and air dried.

2.2.2. Dyeing with Reactive Dyes. The pretreated acrylic samples were introduced into a dyebath of a liquor ratio $40: 1$ at $40^{\circ} \mathrm{C}$ of pHs 2.5 using McIlvaine buffer solutions $[13,14]$ and the temperature was raised to the desired temperature (60$100^{\circ} \mathrm{C}$ ) over $20 \mathrm{~min}$, and then the dyeing was continued at this temperature and under shaking for different time intervals (10-120 min). The dyed samples were removed from the dye pot, rinsed in cold water and soaped with $5 \mathrm{~g} / \mathrm{L}$ nonionic detergent at a liquor ratio of $50: 1$ at $60^{\circ} \mathrm{C}$ for $30 \mathrm{~min}$, rinsed with water and air-dried, and hereinafter called "wash-off 1. "

McIlvaine buffer solution was used to control the $\mathrm{pH}$ of the dyebaths at $\mathrm{pH} 2.5$ during the dyeing process. This $\mathrm{pH}$ was obtained by mixing $3.42 \mathrm{~mL}$ of $0.2 \mathrm{M}$ disodium hydrogen phosphate with $36.58 \mathrm{~mL}$ of $0.1 \mathrm{M}$ citric acid to prepare $40 \mathrm{~mL}$ buffer solution. $\mathrm{pH} 2.5$ was chosen according to our previous report in which higher reactive dye fixation was obtained on amidoximated wool/acrylic blend [7].

\subsection{Measurements and Analyses}

2.3.1. Nitrogen Percentage. The percentage of nitrogen of the blank and pretreated wool/acrylic fabrics was determined by the Kjeldahl method [15]. The average values of three determinations were tabulated.

2.3.2. FTIR Spectroscopy. Fourier transform infrared (FTIR) spectra were recorded on a Nexus 670 FTIR Spectrometer, Nicolet Company, USA, using potassium bromide disks. A total of 32 scans for each sample were taken with a resolution of $4 \mathrm{~cm}^{-1}$, with a range of $4000-400 \mathrm{~cm}^{-1}$.

2.3.3. Tensile Strength. The warp tensile strength was determined for blank and pretreated wool/acrylic fabrics according to the ASTM strip test [16].

2.3.4. Colour Measurements. The relative colour strength of dyed fabrics expressed as $K / S$, where $K$ and $S$ are the absorption and scattering coefficients, respectively, was measured by the light reflectance technique using the Kubelka-Munk equation (1) [17]:

$$
\frac{K}{S}=\frac{(1-R)^{2}}{2 R} .
$$

The reflectance $(R)$ and the levelling properties of dyed samples were measured using a spectrophotometer (Hunter Lab Ultra Scan PRO Spectrophotometer (USA)) interfaced with a personal computer. In order to achieve correct readings, the spectrophotometer was set to exclude any specular components. Five readings per sample of one layer (moving the sample in between) were averaged.

The levelling properties of dyed fabrics using $2 \%$ owf dye applied at the selected dyeing conditions for all dyes were assessed by measuring the colour differences within each sample at five separate points and the average colour difference $(\Delta E)$ between these points was determined [18$20]$.

2.3.5. Dye Exhaustion and Overall Fixation. The extent of dye exhaustion was determined spectrophotometrically. The absorbance of each dyebath solution before and after dyeing process was measured using $1 \mathrm{~cm}$ quartz cells housed in a Shimadzu UV-2401PC UV/visible spectrophotometer at the $\lambda_{\text {max }}$ of each dye. The percentage dyebath exhaustion $(\% E)$ was calculated using (2), where $A_{0}$ and $A_{1}$ are the absorbance of the dyebath before and after dyeing, respectively,

$$
\% E=\frac{A_{0}-A_{1}}{A_{0}} \times 100 .
$$

The extent of reactive dye fixation $(\% F)$ was determined by a method used by several researchers $[5,7,21,22]$ using (3) where $(K / S)_{1}$ and $(K / S)_{2}$ represent the colour strength of 
the dyeing after wash-off 1 and wash-off 2 (the washed sample by wash-off 1 was further washed with a solution containing $5 \mathrm{~g} / \mathrm{L}$ nonionic detergent and $2 \mathrm{~g} / \mathrm{L}$ sodium bicarbonate at a liquor ratio of $50: 1$, at the boil for $30 \mathrm{~min}$, rinsed with water and air dried). This method assumes, at least at the concentration of dyes employed, that $K / S$ values are proportional to concentration of dye on fabric. It is worth mentioning that the fixation value was estimated based on a soaping technique owing to the sensitivity of the pretreated acrylic fabrics to DMF and/or pyridine solution. From both $\% E$ and $\% F$ values, the overall percentage fixation, $\% T$, was evaluated from

$$
\begin{aligned}
& \% F=\frac{(K / S)_{1}}{(K / S)_{2}} \times 100, \\
& \% T=\frac{(\% E \times \% F)}{100} .
\end{aligned}
$$

2.3.6. Fastness Testing. Fastness testing for the dyed samples was tested according to ISO standard methods. The specific tests were ISO 105-X12 (1987), colour fastness to rubbing; ISO 105-C02 (1989), colour fastness to washing; and ISO 105-E04 (1989), colour fastness to perspiration.

\section{Results and Discussion}

The unique reactivity of $\alpha$-nucleophile in amidoxime group and the high uptake of anionic dye in an acid medium due to the presence of this group in the amidoximated acrylic fabrics [4-7] has prompted us to study the viability of reactive dye fixation in an acid medium using different types with different structures so as to find out which mechanism of fixation would be suitable for this type of substrate. For this purpose, amidoximation of acrylic fabrics was made following our previously reported method [4]. The amidoximated acrylic fabrics were then dyed using seven judiciously selected reactive dyes (Figure 1): four reactive dyes based on nucleophilic addition, one reactive dye based on nucleophilic substitution, and two bifunctional reactive dyes, one homobifunctional and the second heterobifunctional reactive dyes. It is needless to mention that the blank acrylic fabrics were nonsubstantive to all dyes used and the fabrics were colourless after being dyed under the appropriate conditions.

\subsection{Amidoximation of Acrylic Fabrics}

3.1.1. Effect of Hydroxylamine Hydrochloride Concentration and Tensile Strength. Table 1 shows the effect of hydroxylamine hydrochloride concentration on the nitrogen content, tensile strength, and elongation at break of amidoximated acrylic fabrics. It is clear that nitrogen content increases as the concentration of hydroxylamine hydrochloride is increased. This result reveals the viability of amidoximation of acrylic fabrics, as the presence of amidoxime groups in the fabric would increase its nitrogen content relative to the blank one (compare nitrile group that has one nitrogen atom and amidoxime group that has two nitrogen atoms). It has been reported that amidoximation of acrylic and wool/acrylic
TABLE 1: Nitrogen content, tensile strength, and elongation at break of blank and modified acrylic fabrics.

\begin{tabular}{lccc}
\hline $\begin{array}{l}\text { Concentration of } \\
\text { hydroxylamine } \\
\text { hydrochloride, g/L }\end{array}$ & $\begin{array}{c}\text { Nitrogen } \\
\text { content } \\
\%\end{array}$ & $\begin{array}{c}\text { Tensile } \\
\text { strength } \\
\text { Kg f }\end{array}$ & $\begin{array}{c}\text { Elongation } \\
\text { at break \% }\end{array}$ \\
\hline Blank & 18.50 & 51.83 & 28.31 \\
2 & 18.76 & 51.54 & 29.20 \\
4 & 18.82 & 50.15 & 29.89 \\
6 & 18.91 & 47.78 & 31.66 \\
8 & 18.93 & 46.00 & 32.88 \\
10 & 18.96 & 44.75 & 33.09 \\
12 & 18.98 & 42.26 & 27.96 \\
14 & 19.10 & 40.95 & 27.00 \\
\hline
\end{tabular}

fabrics resulted in lowering the crystallinity of the fabrics, as evidenced by X-ray data $[3,4]$. Therefore, it is anticipated that the presence of amidoxime groups in the fabrics would render the fabrics more hydrophilic and less crystalline. It is known that the crystallinity of textile fabrics is correlated with the tensile strength for most textile fabrics [5]. Thus, lowering the crystalline phase and increasing the amorphous one of the amidoximated acrylic fabrics as a result of amidoximation would result in decreasing the tensile strength with increasing the concentration of hydroxylamine hydrochloride, as clearly observed in Table 1. Elongation at break, on the other hand, increases going from the blank to the amidoximated samples up to $10 \mathrm{~g} / \mathrm{L}$ hydroxylamine hydrochloride above which the elongation starts to decrease. This result reflects the presence of microvoids present in the amidoximated fabrics due to the formation of amidoxime groups; however, increasing the concentration of hydroxylamine hydrochloride above $10 \mathrm{~g} / \mathrm{L}$ would lead to an excessive amidoximation that produces less flexible fabrics as indicated by a lower value of elongation at break if compared with the blank sample. On the other hand, the tensile strength of amidoximated fabrics decreases more using concentration of hydroxylamine hydrochloride above $10 \mathrm{~g} / \mathrm{L}$. This result is in accordance with our previously reported results of acid dyeing of amidoximated acrylic fabrics, in which amidoximated acrylic fabrics with concentration of hydroxylamine hydrochloride above $10 \mathrm{~g} / \mathrm{L}$ revealed lower dyeability owing to the increased compactness of the pretreated fabrics [4]. Hereinafter, the selected amidoximated fabrics are the one pretreated with $10 \mathrm{~g} / \mathrm{L}$ hydroxylamine hydrochloride. Although this viable approach of amidoximation is a facile pretreatment process using water and nonvolatile soluble salt (hydroxylamine hydrochloride), yet caution has to be taken during the pretreatment owing to the toxicity of hydroxylamine hydrochloride as reported in the MSDS (http://www.sciencelab.com/msds.php?msdsId= 9927192).

\subsection{Dyeing with Reactive Dyes}

3.2.1. Effect of Dyeing Temperature. Recently, the realization of one bath union shade dyeing of pretreated wool/acrylic fabrics was made using McIlvaine buffer solutions at $\mathrm{pH} 2.5$ 
<smiles>CC(=O)Nc1ccc2cc(S(N)(=O)=O)c(/N=N/c3ccc(S(=O)(=O)CCOS(N)(=O)=O)cc3)c(O)c2c1</smiles>

RO16 (A)

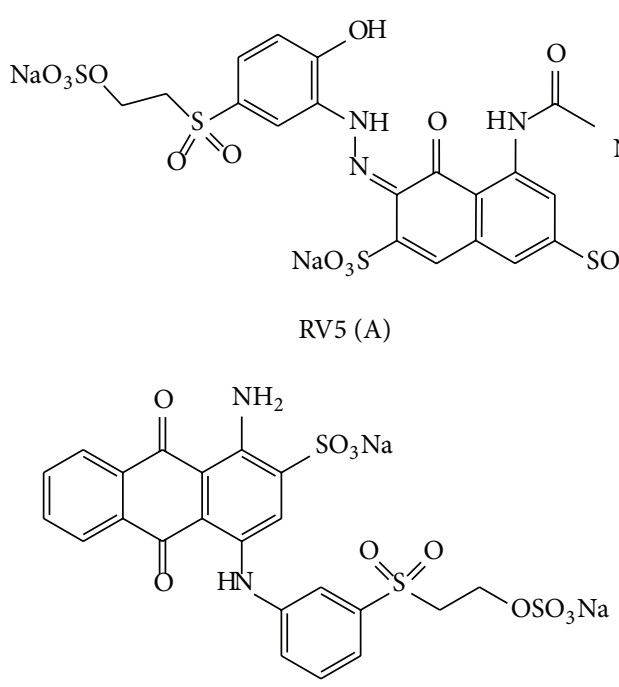

RB19 (A)<smiles>C=C(Br)C(=O)Nc1ccc(N=Nc2c(N)ccc3cc(S(=O)(=O)O[Na])ccc23)c(S(=O)(=O)c2ccc(C)c(S(N)(=O)=O)c2)c1</smiles>

RR84 (A)<smiles>CS(=O)(=O)OCCS(=O)(=O)c1cccc(Nc2nc(Cl)nc(Nc3cc4c(c(OS(C)(=O)=O)c3)C(=O)C(=NNc3ccc5c(SO)cccc5c3S(C)(=O)=O)C(S(C)(=O)=O)=C4)n2)c1</smiles>

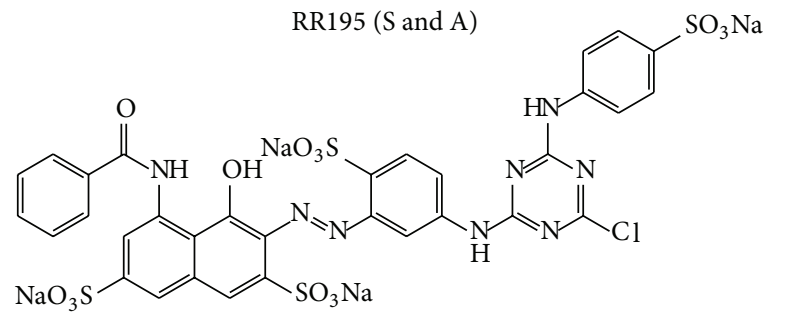

RR4 (S)

FIGURE 1: Nucleophilic substitution (S) and nucleophilic addition (A) type reactive dyes.

and in a dyebath of $40: 1$ liquor ratio [7]. These dyeing conditions of $\mathrm{pH}$ and liquor ratio were applied in the coloration of amidoximated acrylic fabrics using different reactive dyes and at different temperature and time so as to find out which mechanism of dyeing is suitable for such type of acrylic polymer. The effect of dyeing temperature on the dyeability of amidoximated acrylic fabrics with different reactive dyes is shown in Figures 2-4. It can be seen that the colour data represented as the colour strength, exhaustion, and total fixation values increase with the dyeing temperature. It is generally accepted that the dyeability enhancement upon heating is ought to the fabric swelling and, hence, better dye diffusion. In this context, the presence of amidoxime groups in the amidoximated acrylic fabrics as the active dye sites would facilitate dye uptake. It is worth noting the difference in the dyeability shown in Figures 2 and 3 in relation to the dye type. Figure 2 compares the dyeability of amidoximated acrylic fabrics between RB19 that contains sulphatoethylsulphone (SES) group as a nucleophilic addition type reactive dye and RR4 that contains monochlorotriazine (MCT) group as a nucleophilic substitution type reactive dye. It is clear from the figure that the colour data obtained by nucleophilic addition are far better than those obtained by nucleophilic substitution. The result confirms that the selected $\mathrm{pH}$ was suitable for dye fixation using nucleophilic addition type reactive dyes but not for nucleophilic substation type ones. It seems that such low acidic $\mathrm{pH}$ even though it is good for dye exhaustion, it is not good for dye fixation using nucleophilic substation type reactive dyes owing to acid hydrolysis.

On the other hand, Figure 3 compares the dyeability of amidoximated acrylic fabrics between RR195 that contains SES group and MCT group (nucleophilic addition and nucleophilic substitution type reactive dye) and RB171 that contains two MCT groups (nucleophilic substitution 


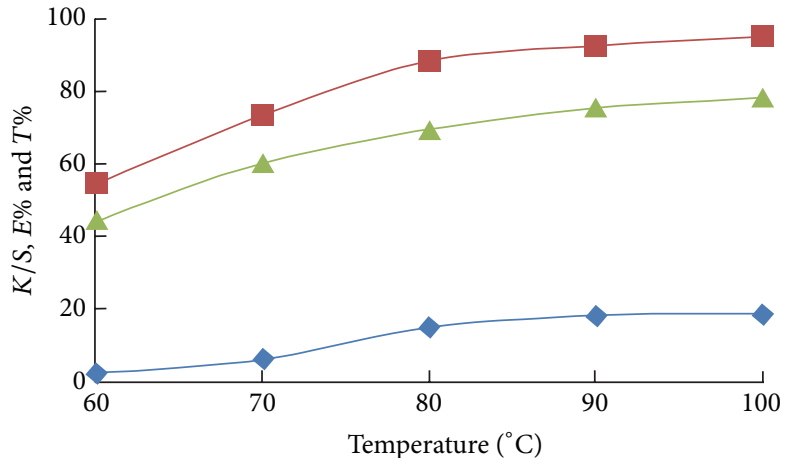

$-K / S(\mathrm{RB} 19)$
$-\quad E \%(\mathrm{RB} 19)$
$T \%(\mathrm{RB} 19)$

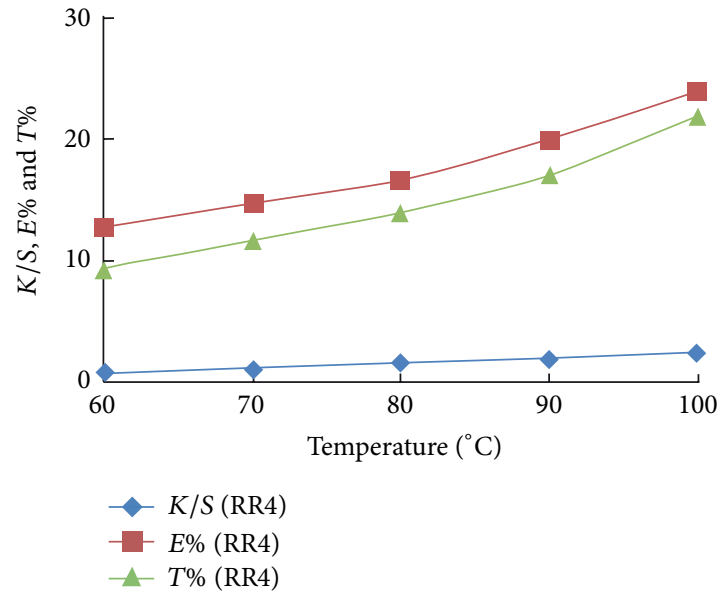

(b)

Figure 2: Effect of temperature on the exhaustion, total fixation, and colour strength of CI reactive blue 19 (A) and CI reactive red 4 (S) on amidoximated acrylic fabrics; dyeing conditions: shade $2 \%$ owf, liquor ratio $40: 1, \mathrm{pH} 2.5$, for 60 min.

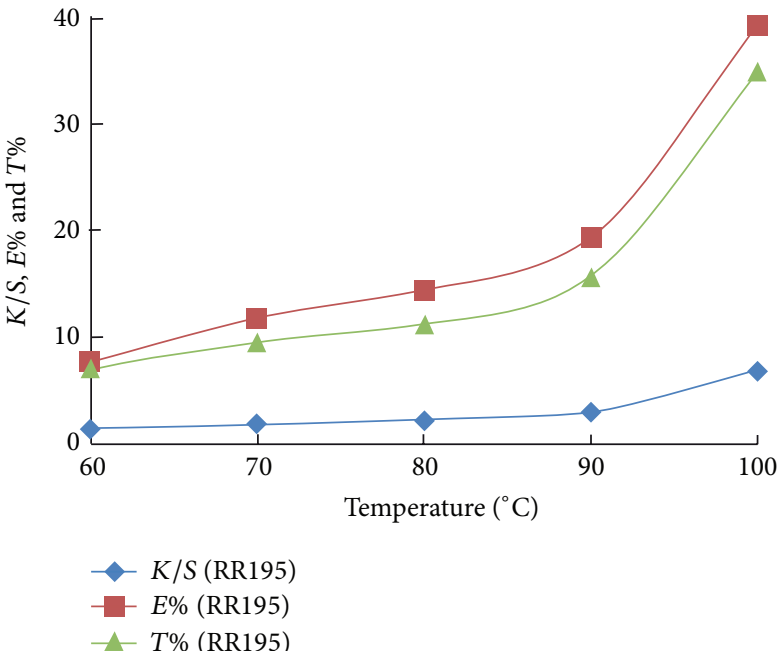

(a)

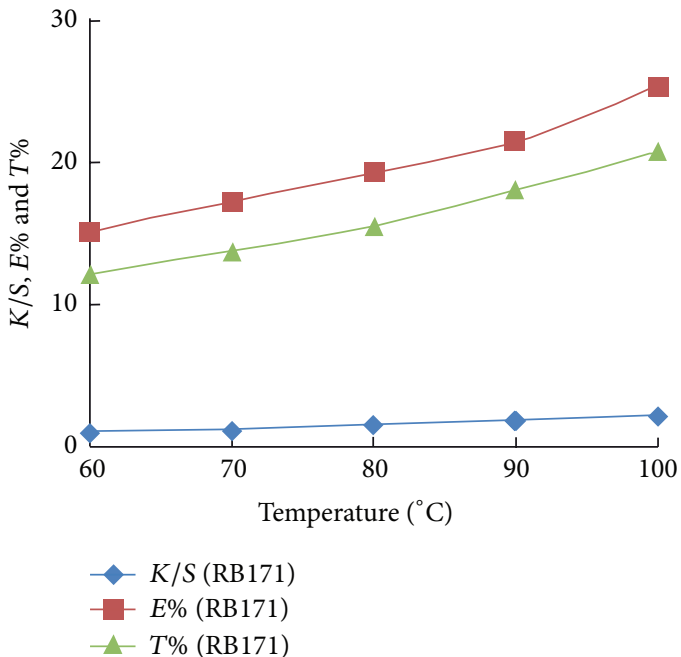

(b)

FIGURE 3: Effect of temperature on the exhaustion, total fixation and colour strength of CI Reactive Red 195 (heterobifunctional reactive dye) and CI Reactive Blue 171 (homobifunctional reactive dye) on amidoximated acrylic fabrics; dyeing conditions: shade $2 \%$ owf, liquor ratio $40: 1, \mathrm{pH} 2.5$, for $60 \mathrm{~min}$.

type reactive dye). As expected, hetero bifunctional reactive dye resulted in a better colour data than those obtained by homobifunctional reactive dye owing to the presence of SES reactive site. However, the overall data of heterobifunctional reactive dye is not as high as of monofunctional nucleophilic addition type reactive dyes, which could be attributed to the lower affinity of RR195 due to its molecular size. This result confirms further the suitability of nucleophilic addition type reactive dyes for obtaining viable dyeing characteristics on amidoximated acrylic fabrics. However, the colour data obtained by RR195 was inferior to those obtained by RB19 and RR84. This result may be attributed to the molecular size effect and its impact on the dyeability. The smaller molecular size of RB19 and RR84 compared with RR195 (see Figure 1) may help further dye diffusion and thus better dye exhaustion.

Additionally, the effect of temperature on the dyeability of amidoximated acrylic fabrics was investigated using another two SES type reactive dyes, namely, RO16 and RV5 and RR84 that contains $\alpha$-bromoacrylamide group as a nucleophilic addition type reactive dye. The results shown in Figure 4 support further the above findings of the good colour data obtained using nucleophilic addition type reactive dyes.

3.2.2. Effect of Dyeing Time. Figure 5 shows the effect of dyeing time on the colour strength, exhaustion, and total fixation 


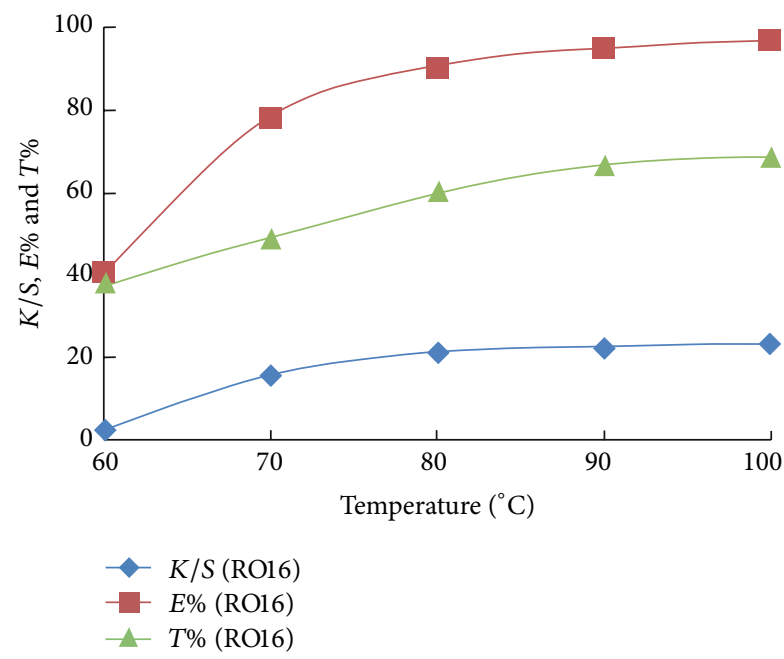

(a)

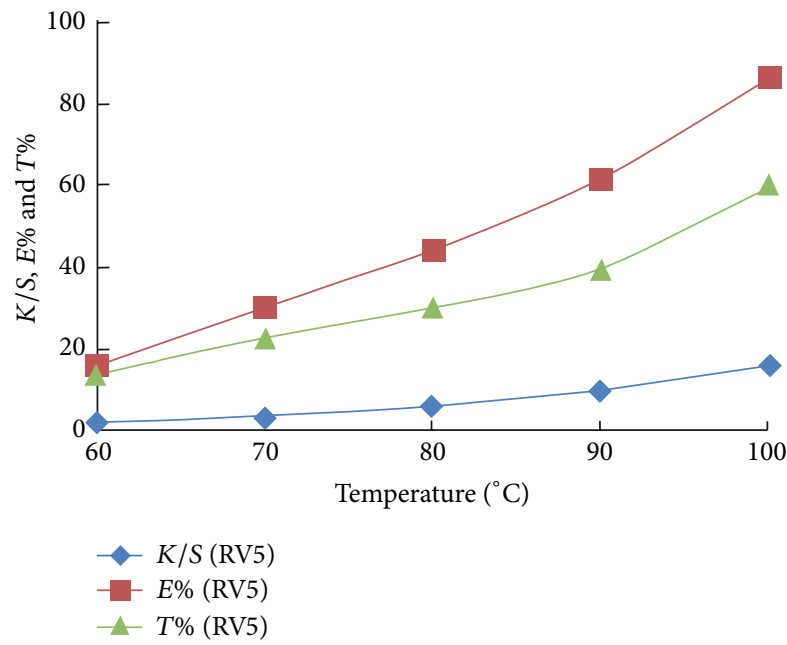

(b)

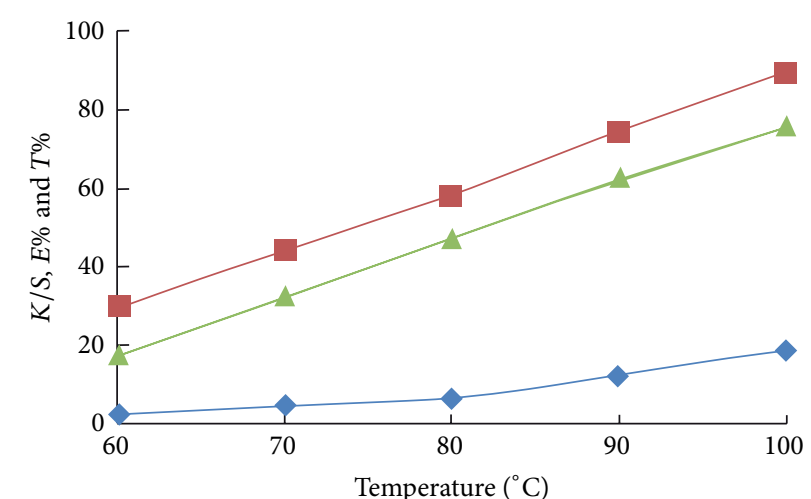

K/S (RR84)

$E \%(\mathrm{RR} 84)$

$T \%(\mathrm{RR} 84)$

(c)

FIGURE 4: Effect of temperature on the exhaustion, total fixation, and colour strength of CI Reactive Orange 16 (A), CI Reactive Violet 5 (A), and CI Reactive Red 84 (A) on amidoximated acrylic fabrics; dyeing conditions: shade 2\% owf, liquor ratio $40: 1$, pH 2.5 , for 60 min.

of RB19, RO16, RV5, and RR84 on amidoximated acrylic fabrics. As indicated, the colour data increase with the dyeing time up to $60 \mathrm{~min}$ above which either a plateau is reached as in the case of RV5 and RB19 or a little decline in the dyeability takes place. It is known that the dyeing process proceeds via surface adsorption of dye molecules, sorption, diffusion, and dye-fabric fixation. This process reaches an equilibrium at certain time at which the sorption and desorption of the dye molecules are equal; however, prolonged dyeing time at such high temperature $\left(100^{\circ} \mathrm{C}\right)$ would facilitate dye desorption as indicated in the values of colour strength and exhaustion values. The desorbed dye at such conditions could be attributed to the noncovalently fixed dyes and/or the hydrolyzed ones.

3.2.3. Total Fixation of Reactive Dyes. The remarkable high fixation values for RB19, RO16, RV5, and RR84 at such low acidic $\mathrm{pH}$ are attributed to the presence of amidoxime groups in the amidoximated acrylic fabrics. It is known that amidoxime group is an $\alpha$-nucleophile type [8-10] in which $\mathrm{O}$-nucleophile is the reaction site. Also, this acidic $\mathrm{pH}$ would favour the enhancement of dye exhaustion by virtue of ionic bond formation between the sulfonate groups present in the dye molecules and the protonated amino groups present in the amidoximated acrylic fabrics. This dye fixation mechanism can be schematized in Figure 6 . Thus, SES containing reactive dyes (RB19, RO16, and RV5) get activated at high temperature to produce the Michael reactive form (vinyl sulfone) in which, upon being in close proximity with O-nucleophile present in the amidoximated fabrics, a covalent bond takes place via Michael addition mechanism. Also, Michael addition mechanism takes place between $\alpha$-bromoacrylamide reactive dye (RR84) with the amidoximated acrylic fabrics. 


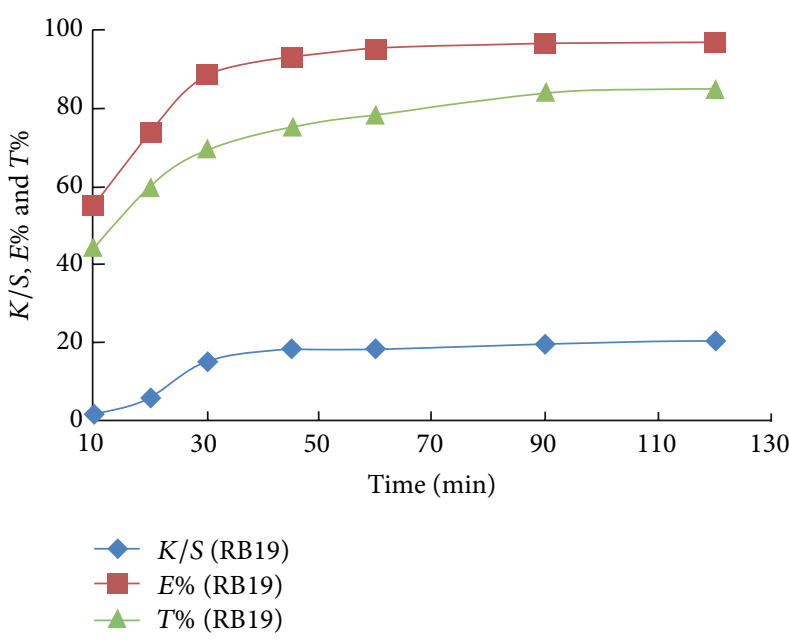

(a)

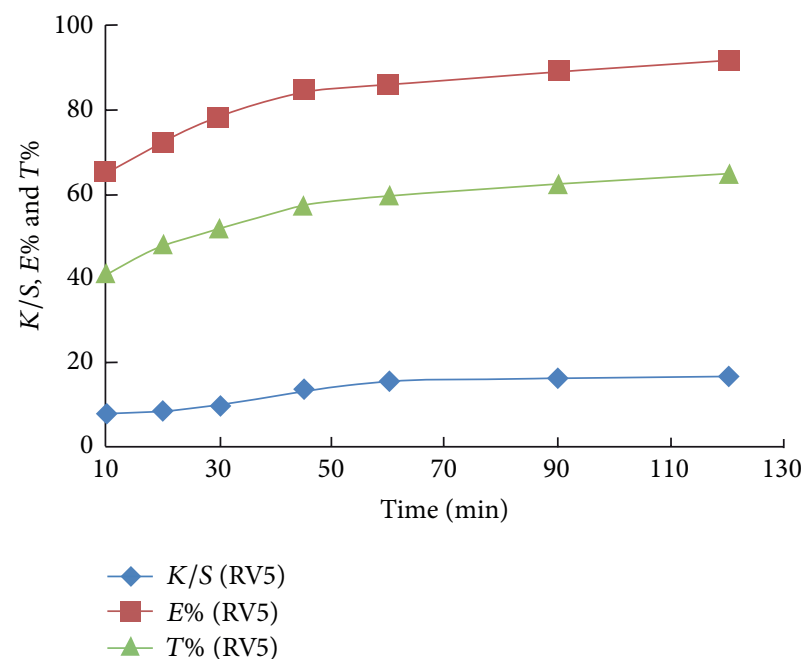

(c)

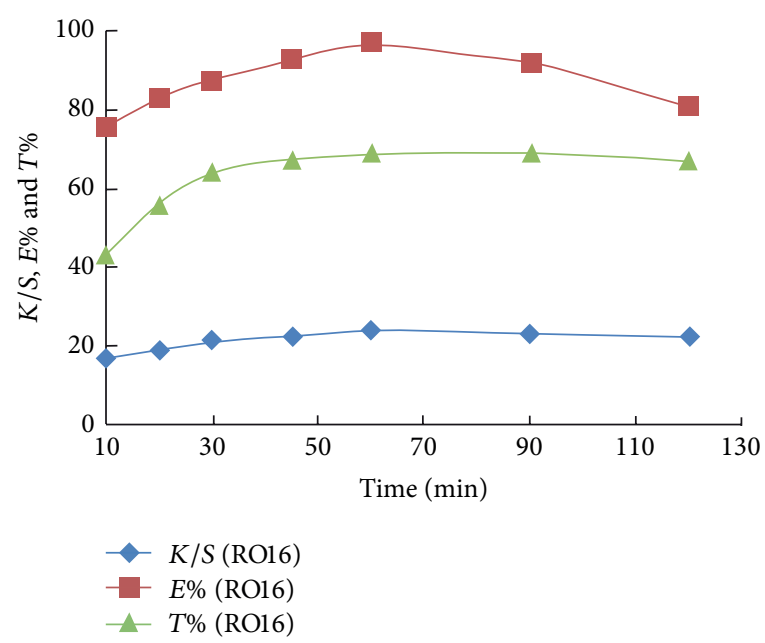

(b)

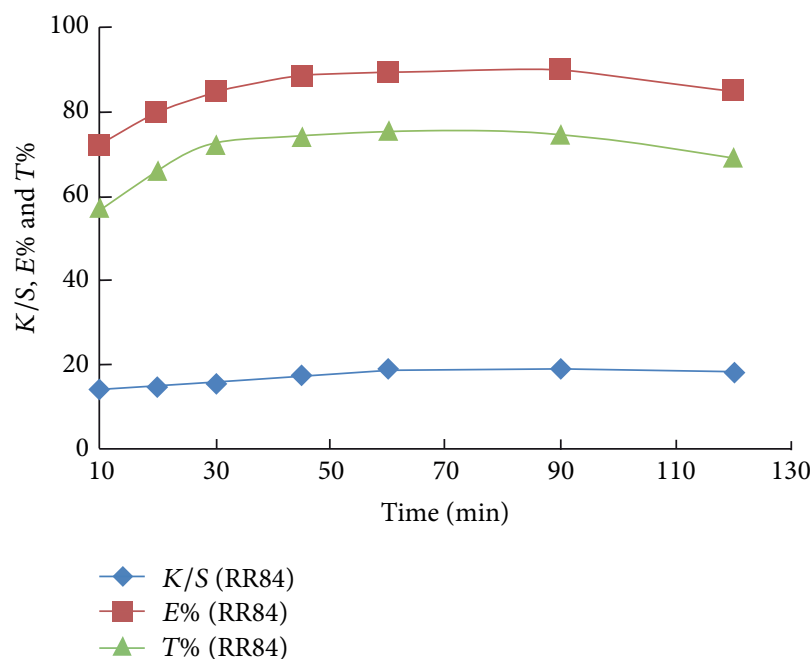

(d)

Figure 5: Colour strength, exhaustion, and total fixation of amidoximated acrylic fabrics using nucleophilic addition type reactive dyes of different structures as a function of time; dyeing conditions: shade $2 \%$ owf, liquor ratio $40: 1, \mathrm{pH} 2.5$, at $100^{\circ} \mathrm{C}$.

3.2.4. FTIR Analysis. FTIR spectra were made to further confirm the changes in the characteristic peaks of amidoxime groups present in the amidoximated acrylic fabrics after being dyed with reactive dyes. As elaborated above, only nucleophilic addition type reactive dyes are the one suitable for such type of fabrics and therefore three dyes of them are selected for FTIR analysis. The selected dyes are RB19, RO16, and RR84. RV5 was not selected as it is similar to RO16.

Figures 7, 8, and 9 show the FTIR spectra of amidoximated acrylic fabrics, the dye, and the fabric after being dyed with reactive dyes. The reaction of hydroxylamine hydrochloride with acrylic fabrics has partially converted some of the nitrile groups into amidoxime groups. Full FTIR data for the fabrics before and after pretreatment with hydroxylamine hydrochloride and has previously been reported by the present authors [4]. A characteristic band of nitrile groups at $2243 \mathrm{~cm}^{-1}$ is present on the surface of the fabric before and after dyeing. The characteristic $\mathrm{C}=\mathrm{N}$ groups characterized by the band at $1594 \mathrm{~cm}^{-1}$. The broadband at $3150-3550 \mathrm{~cm}^{-1} \mathrm{can}$ be attributed to $\mathrm{H}$-bondings of $\mathrm{NH}_{2}$ and $\mathrm{O}-\mathrm{H}$ in the amidoxime groups.

Tables 2, 3, and 4 summarize FTIR peaks for the amidoximated acrylic fabrics before and after dyeing with RB19, RO16, and RR84, respectively. Upon dyeing with reactive dyes, a shift was observed in the stretching band of $\mathrm{N}-\mathrm{O}$ and $\mathrm{C}=\mathrm{N}$. This shift indicates the involvement of amidoxime groups in the fixation mechanism as shown in Figures 7-9. Also, the stretching band for $\mathrm{OH}$ and $\mathrm{NH}_{2}$ appeared with less intensity in the dyed fabrics using RB19 or RO16 as a consequence of losing the $\mathrm{OH}$ group in the fixation mechanism. However, using dye RR84, the stretching band before and after dyeing appeared with more intensity owing to the intensity contributed by the amino group present in the dye molecule. Furthermore, the presence of different bands in 
TABLE 2: FT-IR characteristic absorption peaks of modified acrylic fibers, RB19, and modified acrylic fabrics dyed with RB19.

\begin{tabular}{lccc}
\hline \multirow{2}{*}{ Peak assignment } & \multicolumn{2}{c}{ Wavenumber $\left(\mathrm{cm}^{-1}\right)$} \\
& Modified acrylic fibers & RB19 & Modified acrylic fibers dyed with RB19 \\
\hline N-O stretching, amidoxime & 947 & - & 930 \\
$\mathrm{C}=\mathrm{N}$ stretching, amidoxime & 1594 & - & 1575 \\
$\mathrm{OH}$ and $\mathrm{NH}_{2}$ stretching, amidoxime & $3150-3550$, broad & - & Present with less intensity \\
$\mathrm{CN}$ stretching, nitrile & 2243 & - & 2243 \\
$\mathrm{~S}=\mathrm{O}$ stretching, suffonic group & - & $1040,1140,1228$ & Present overlapped with less intensity at 1228 \\
$\mathrm{C}=\mathrm{O}, \mathrm{C}=\mathrm{C}$, conjugated carbonyl with aromatic & - & $1500-1670$ & Present overlapped with less intensity at 1659 \\
\hline
\end{tabular}
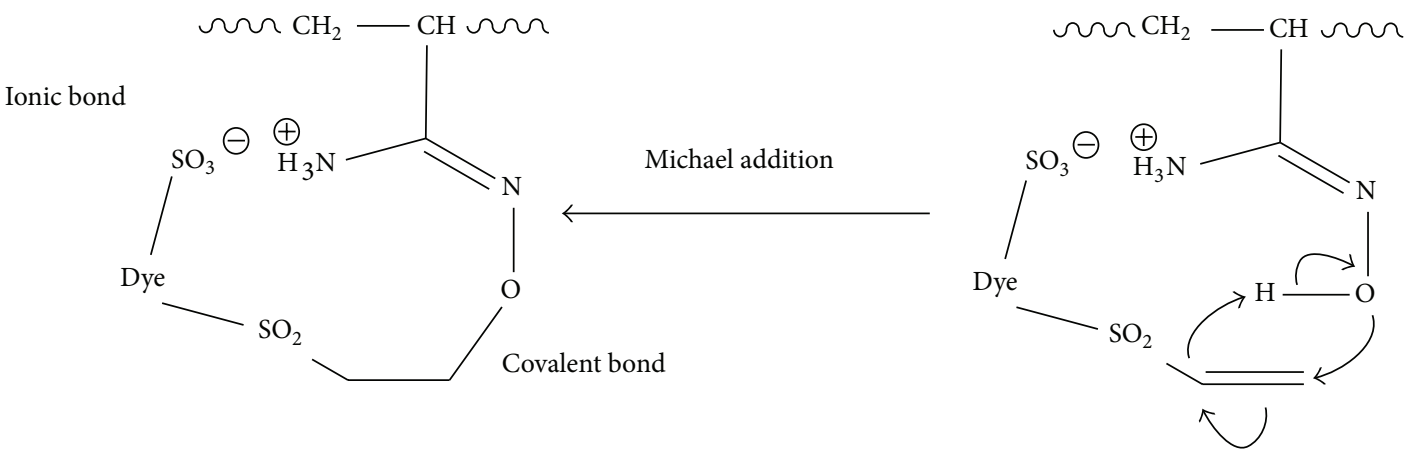

Vinyl sulfone reactive dyes (RB19, RO16, and RV5)
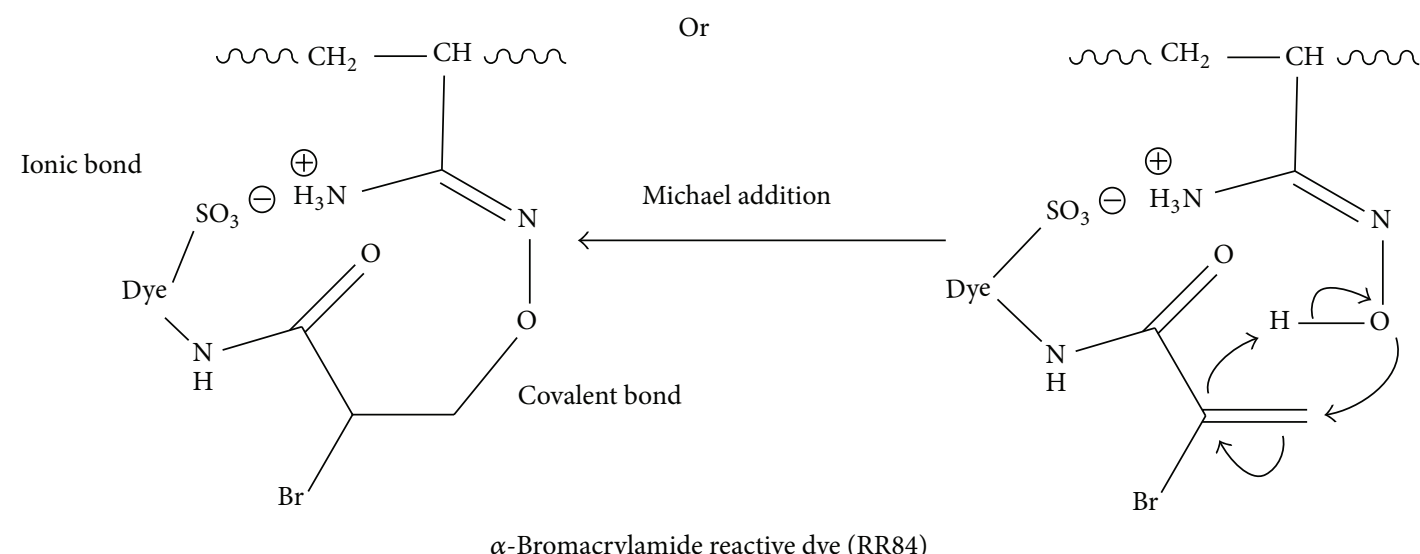

FIGURE 6: Fixation mechanism of reactive dyes on amidoximated acrylic fibres. 
TABLE 3: FT-IR characteristic absorption peaks of modified acrylic fibers, RO16, and modified acrylic fabrics dyed with RO16.

\begin{tabular}{|c|c|c|c|}
\hline \multirow{2}{*}{ Peak assignment } & \multicolumn{3}{|c|}{ Wavenumber $\left(\mathrm{cm}^{-1}\right)$} \\
\hline & Modified acrylic fibers & RO16 & Modified acrylic fibers dyed with RO16 \\
\hline $\mathrm{N}-\mathrm{O}$ stretching, amidoxime & 947 & - & 968 \\
\hline $\mathrm{C}=\mathrm{N}$ stretching, amidoxime & 1594 & - & 1596 \\
\hline $\mathrm{OH}$ and $\mathrm{NH}_{2}$ stretching, amidoxime & 3150-3550, broad & - & Present with more intensity \\
\hline $\mathrm{CN}$ stretching, nitrile & 2243 & - & 2243 \\
\hline $\mathrm{S}=\mathrm{O}$ stretching, sulfonic group & - & $1049,1136,1288$ & Present overlapped with less intensity at 1238 \\
\hline Para-disubstituted benzene & - & 836 & Present with less intensity at 828 \\
\hline
\end{tabular}

TABLE 4: FT-IR characteristic absorption peaks of modified acrylic fibers, RR84, and modified acrylic fabrics dyed with RR84.

\begin{tabular}{lccc}
\hline Peak assignment & & & Wavenumber $\left(\mathrm{cm}^{-1}\right)$ \\
& Modified acrylic fibers & RR84 & Modified acrylic fibers dyed with RR84 \\
\hline N-O stretching, amidoxime & 947 & - & 926 \\
$\mathrm{C}=\mathrm{N}$ stretching, amidoxime & 1594 & - & 1632 overlapped with $\mathrm{C}=\mathrm{C}$ aromatic and C=O amide \\
$\mathrm{OH}$ and $\mathrm{NH}_{2}$ stretching, amidoxime & $3150-3550$, broad & - & Present with more intensity \\
$\mathrm{CN}$ stretching, nitrile & 2243 & - & 2243 \\
$\mathrm{C}=\mathrm{C}$ aromatic, $\mathrm{C}=\mathrm{O}$ amide & - & 1585, 1626, 1662 & Overlapped with C=N amidoxime with less intensity at 1632 \\
$\mathrm{C}-\mathrm{Br}$ stretching & - & 831 & Present with less intensity at 848 \\
\hline
\end{tabular}

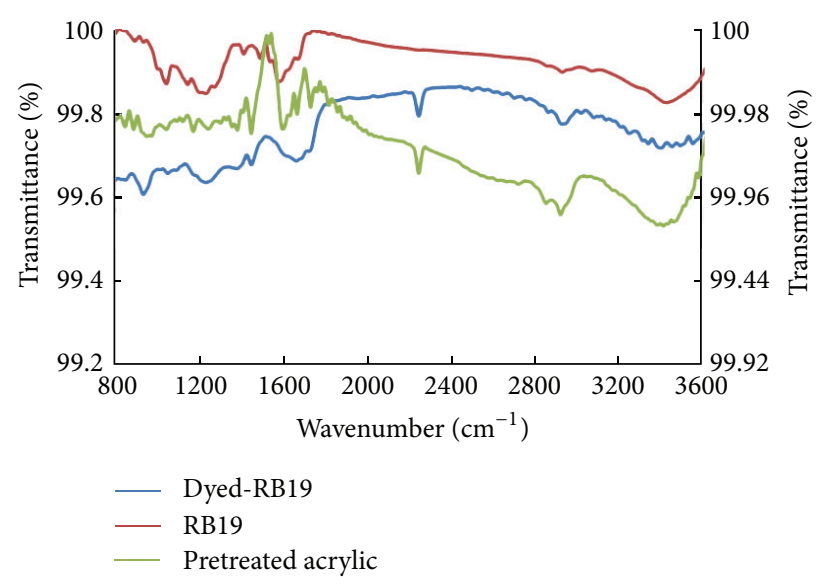

FIGURE 7: FTIR of amidoximated acrylic fibres, RB19, and amidoximated acrylic fabrics dyed with RB19; dyeing conditions: shade $2 \%$ owf, liquor ratio $40: 1, \mathrm{pH} 2.5$, at $100^{\circ} \mathrm{C}$ for $60 \mathrm{~min}$.

the dyed fabrics due to the stretching of sulfonic groups, carbonyl groups, bromide atoms, and the aromatic stretching vibrations with shift compared with those bands before dyeing indicated the binding of reactive dyes with the fabrics.

3.2.5. The Levelling Properties. The levelling properties of dyed amidoximated acrylic fabrics are shown in Figure 10. It is clearly observed that the average colour differences $(\Delta E)$ of the dyed samples show good levelling properties in all cases $(\Delta E$ less than 1$)$. It is worth noting the difference in

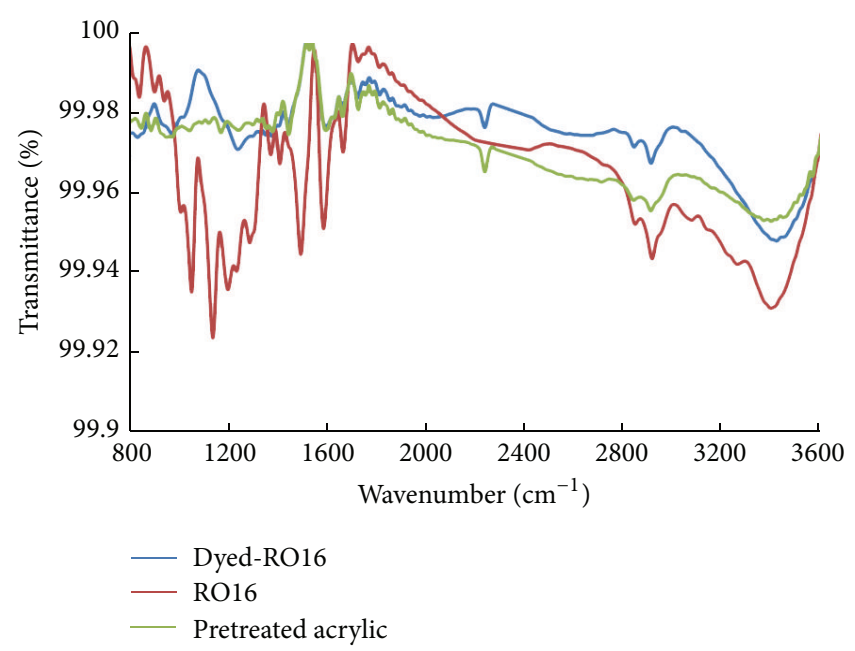

FIGURE 8: FTIR of amidoximated acrylic fibres, RO16, and amidoximated acrylic fabrics dyed with RO16; dyeing conditions: shade $2 \%$ owf, liquor ratio $40: 1, \mathrm{pH} 2.5$, at $100^{\circ} \mathrm{C}$ for $60 \mathrm{~min}$.

the number of water solubilizing groups in the four reactive dyes shown in Figure 1. Both RB19 and RO16 have one sulfonic group, whereas both RR84 and RV5 have two sulfonic groups. Therefore, it is anticipated that RB19 and RO16 are less hydrophilic than RR84 and RV5 and as a consequence both RB19 and RO16 would reveal higher affinity to the amidoximated acrylic than those of RR84 and RV5. Indeed the $E \%$ and $T \%$ values of RB19 and RO16 are higher than those of RR84 and RV5. This high exhaustion values are 
TABLE 5: Fastness properties of dyed modified acrylic fabrics.

\begin{tabular}{|c|c|c|c|c|c|c|c|c|c|c|c|c|c|c|}
\hline \multirow{2}{*}{ Reactive dyes $^{\mathrm{a}}$} & \multicolumn{4}{|c|}{ Wash Fastness } & \multicolumn{4}{|c|}{ Acid perspiration } & \multicolumn{4}{|c|}{ Alkali perspiration } & \multicolumn{2}{|c|}{ Rubbing fastness } \\
\hline & St. ${ }^{*}$ & St. ${ }^{* *}$ & St. ${ }^{* * *}$ & Alt. & St. ${ }^{*}$ & St. ${ }^{* *}$ & St. ${ }^{* * *}$ & Alt. & St. ${ }^{*}$ & $\mathrm{St}^{* *}$ & St. ${ }^{* * *}$ & Alt. & Dry & Wet \\
\hline RO16 & $4-5$ & $4-5$ & $4-5$ & $4-5$ & 4 & $4-5$ & $4-5$ & $4-5$ & 4 & $4-5$ & $4-5$ & $4-5$ & $3-4$ & 3 \\
\hline RV5 & 4 & $4-5$ & $4-5$ & $4-5$ & $4-5$ & $4-5$ & $4-5$ & $4-5$ & 4 & $4-5$ & $4-5$ & $4-5$ & $4-5$ & 3 \\
\hline RB19 & 4 & 4 & $4-5$ & $4-5$ & 4 & $4-5$ & $4-5$ & $4-5$ & 4 & $4-5$ & $4-5$ & $4-5$ & $4-5$ & $3-4$ \\
\hline RR84 & $4-5$ & $4-5$ & $4-5$ & $4-5$ & $4-5$ & $4-5$ & $4-5$ & $4-5$ & 4 & $4-5$ & $4-5$ & $4-5$ & 3 & $2-3$ \\
\hline RR4 & $4-5$ & $4-5$ & $4-5$ & $4-5$ & $4-5$ & $4-5$ & $4-5$ & $4-5$ & $4-5$ & $4-5$ & $4-5$ & $4-5$ & 3 & $2-3$ \\
\hline $\mathrm{RB} 171$ & $4-5$ & $4-5$ & $4-5$ & $4-5$ & $4-5$ & $4-5$ & $4-5$ & $4-5$ & $4-5$ & $4-5$ & $4-5$ & $4-5$ & $3-4$ & 3 \\
\hline RR195 & $4-5$ & $4-5$ & $4-5$ & $4-5$ & $4-5$ & $4-5$ & $4-5$ & $4-5$ & $4-5$ & 4-5 & $4-5$ & $4-5$ & 4 & 3 \\
\hline
\end{tabular}

${ }^{*}$ St. $=$ staining on cotton. ${ }^{* *}$ St. $=$ staining on wool. ${ }^{* * *}$ St. $=$ staining on acrylic. Alt. $=$ alteration.

${ }^{a}$ Reactive dyeing condition: shade $2 \%$ owf, LR $40: 1, \mathrm{pH} 2.5$, at $100^{\circ} \mathrm{C}$ for $60 \mathrm{~min}$.

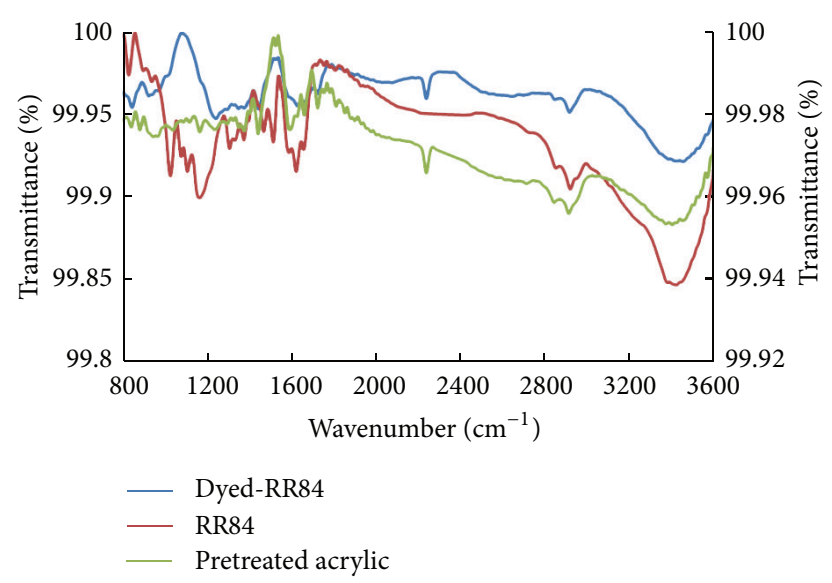

FIGURE 9: FTIR of amidoximated acrylic fibres, RR84, and amidoximated acrylic fabrics dyed with RR84; dyeing conditions: shade $2 \%$ owf, liquor ratio $40: 1, \mathrm{pH} 2.5$, at $100^{\circ} \mathrm{C}$ for $60 \mathrm{~min}$.

also reflected in the good leveling properties for these dyes compared with those of RR84 and RV5.

3.3. Fastness Properties. As shown in Table 5, the fastness tests of washing, rubbing, and perspiration of samples that had been dyed with the reactive dyes are excellent to good indicating the existence of strong bonds (ionic and covalent bonds) between the dye molecules and the amidoximated acrylic fabrics. However, the wet rubbing fastness of dye RR4 and RR84 is fair. This result may be explained by the aggregation and/or surface coloration of these dyes.

\section{Conclusion}

Amidoximated acrylic fabrics could be dyed successfully with high fixation at acidic $\mathrm{pH}$ using nucleophilic addition type reactive dyes. Excellent to good fastness and levelling properties were obtained. Compared with substitution type reactive dyes, the results confirm the suitability nucleophilic addition type reactive dyes, which have small molecular sizes

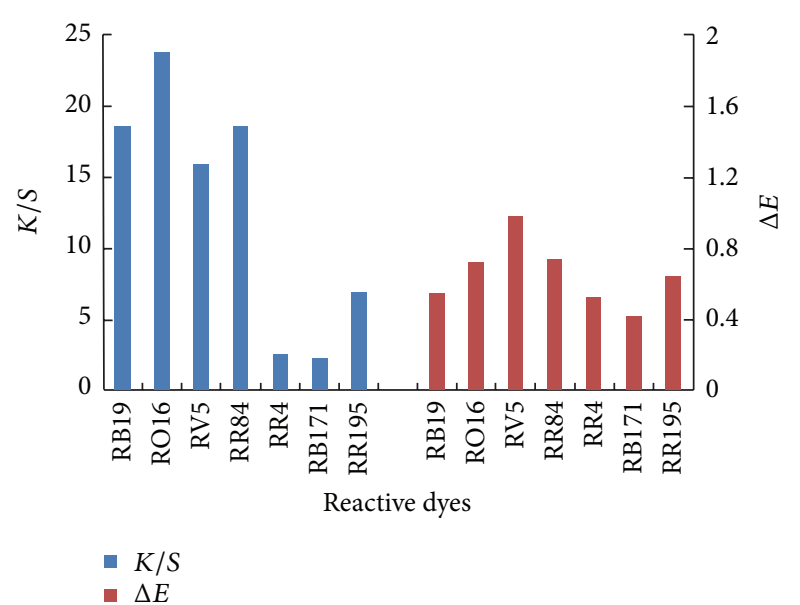

FIGURE 10: Comparative colour difference and colour strength of different reactive dyes on amidoximated acrylic fabrics; dyeing conditions: shade $2 \%$ owf, liquor ratio $40: 1, \mathrm{pH} 2.5$, at $100^{\circ} \mathrm{C}$ for $60 \mathrm{~min}$.

for the colouration of amidoximated acrylic fabrics. This finding is expected to pave the way for industry related textile colouration of acrylic fabrics and its blends with a variety of colours and dye classes.

\section{Conflict of Interests}

The authors declare that there is no conflict of interests regarding the publication of this paper.

\section{References}

[1] V. B. Gupta and V. K. Kothari, Manufactured Fiber Technology, Chapman Hall, New York, NY, USA, 1997.

[2] L. K. El Gabry, "Effect of mineral acids on the properties of acrylic fabrics," Coloration Technology, vol. 120, no. 5, pp. 236240, 2004.

[3] K. Xie and A. Hou, "One-bath dyeing of wool/acrylic blends with reactive cationic dyes based on monofluorotriazine," Coloration Technology, vol. 120, no. 6, pp. 307-310, 2004. 
[4] R. M. El-Shishtawy and N. S. E. Ahmed, "Anionic coloration of acrylic fibre. Part 1: efficient pretreatment and dyeing with acid dyes," Coloration Technology, vol. 121, no. 3, pp. 139-146, 2005.

[5] R. M. El-Shishtawy, S. H. Nassar, and N. S. E. Ahmed, "Anionic colouration of acrylic fibre. Part II: printing with reactive, acid and direct dyes," Dyes and Pigments, vol. 74, no. 1, pp. 215-222, 2007.

[6] R. M. El-Shishtawy, G. M. Shokry, N. S. E. Ahmed, and M. M. Kamel, "Dyeing of modified acrylic fibers with curcumin and madder natural dyes," Fibers and Polymers, vol. 10, no. 5, pp. 617624, 2009.

[7] R. M. El-Shishtawy, M. M. El-Zawahry, and N. S. E. Ahmed, "One-bath union dyeing of a modified wool/acrylic blend with acid and reactive dyes," Coloration Technology, vol. 127, no. 1, pp. 28-38, 2011.

[8] Y. S. Simanenko, T. M. Prokop'eva, I. A. Belousova, A. F. Popov, and E. A. Karpichev, "Amidoximes as effective acceptors of acyl group," Theoretical and Experimental Chemistry, vol. 37, no. 5, pp. 288-295, 2001.

[9] T. M. Prokop'eva, Y. S. Simanenko, E. A. Karpichev, V. A. Savelova, and A. F. Popov, "O-nucleophilic features of amidoximes in acyl group transfer reactions," Russian Journal of Organic Chemistry, vol. 40, no. 11, pp. 1617-1629, 2004.

[10] B. A. Trofimov, E. Y. Schmidt, A. I. Mikhaleva, A. M. Vasilt'sov, and A. V. Afonin, "An unusually fast nucleophilic addition of amidoximes to acetylene," Mendeleev Communications, vol. 10, no. 1, pp. 29-30, 2000.

[11] W. Herbst and K. Hunger, Industrial Organic Pigments, Production, Properties, Applications, WILEY-VCH, GmbH \& Co. KGaA, Weinheim, Germany, 3rd edition, 2003.

[12] A. D. Broadbent, Basic Principles of Textile Colouration, Society of Dyers and Colourist, Bradford, UK, 2001.

[13] D. D. Perrin and B. Dempsey, Buffers for $p H$ and Metal Ion Control, Chapman and Hall, London, UK, 1987.

[14] A. Vogel, Textbook of Quantitative Inorganic Analysis, Longmans, London, UK, 1944.

[15] A. I. Vogel, "Elementary practical organic chemistry," in Quantitative Organic Analysis, Longman, London, UK, 2nd edition, 1975.

[16] ASTM Standard Test Method, Breaking Load and Elongation of Textile Fabric, D-1682-94, ASTM, West Conshohocken, 1994.

[17] D. B. Judd and G. Wysezcki, Colour in Business, Science and Industry, John Wiley \& Sons, New York, NY, USA, 3rd edition, 1975.

[18] R. M. El-Shishtawy, Y. A. Youssef, N. S. E. Ahmed, and A. A. Mousa, "Acid dyeing isotherms of cotton fabrics pretreated with mixtures of reactive cationic agents," Coloration Technology, vol. 120, no. 4, pp. 195-200, 2004.

[19] J. Koh, J. D. Kim, and J. P. Kim, "Synthesis and application of a temporarily solubilised alkali-clearable azo disperse dye and analysis of its conversion and hydrolysis behaviour," Dyes and Pigments, vol. 56, no. 1, pp. 17-26, 2003.

[20] R. M. El-Shishtawy, Y. A. Youssef, N. S. E. Ahmed, and A. A. Mousa, "The use of sodium edate in dyeing: II. Union dyeing of cotton/wool blend with hetero bi-functional reactive dyes," Dyes and Pigments, vol. 72, no. 1, pp. 57-65, 2007.

[21] M. M. Kamel, R. M. El-Shishtawy, H. L. Hanna, and N. S. E. Ahmed, "Ultrasonic-assisted dyeing: I. Nylon dyeability with reactive dyes," Polymer International, vol. 52, no. 3, pp. 373-380, 2003.
[22] A. Soleimani-Gorgani and J. A. Taylor, "Dyeing of nylon with reactive dyes. Part 1 . The effect of changes in dye structure on the dyeing of nylon with reactive dyes," Dyes and Pigments, vol. 68, no. 2-3, pp. 109-117, 2006. 

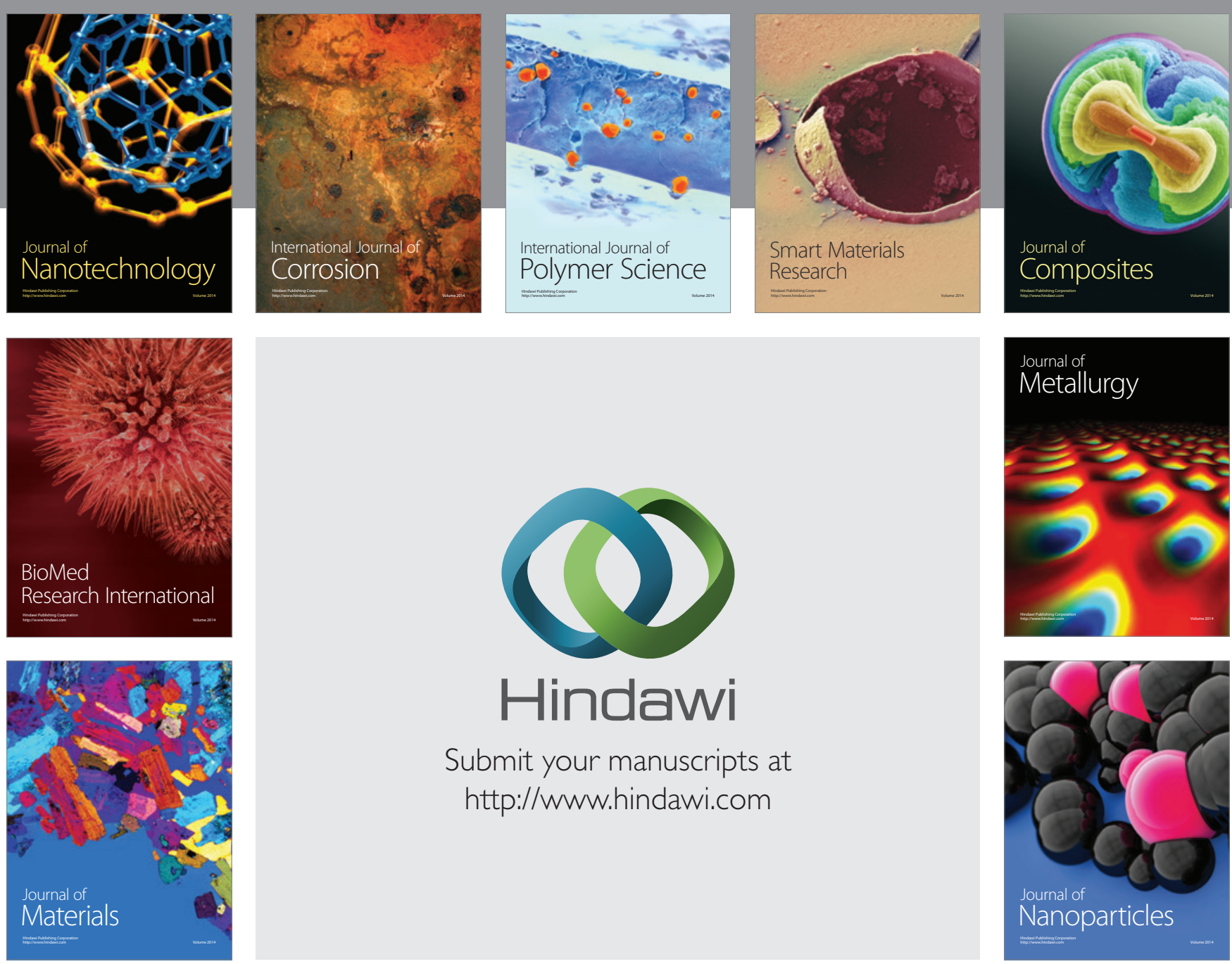

Submit your manuscripts at http://www.hindawi.com
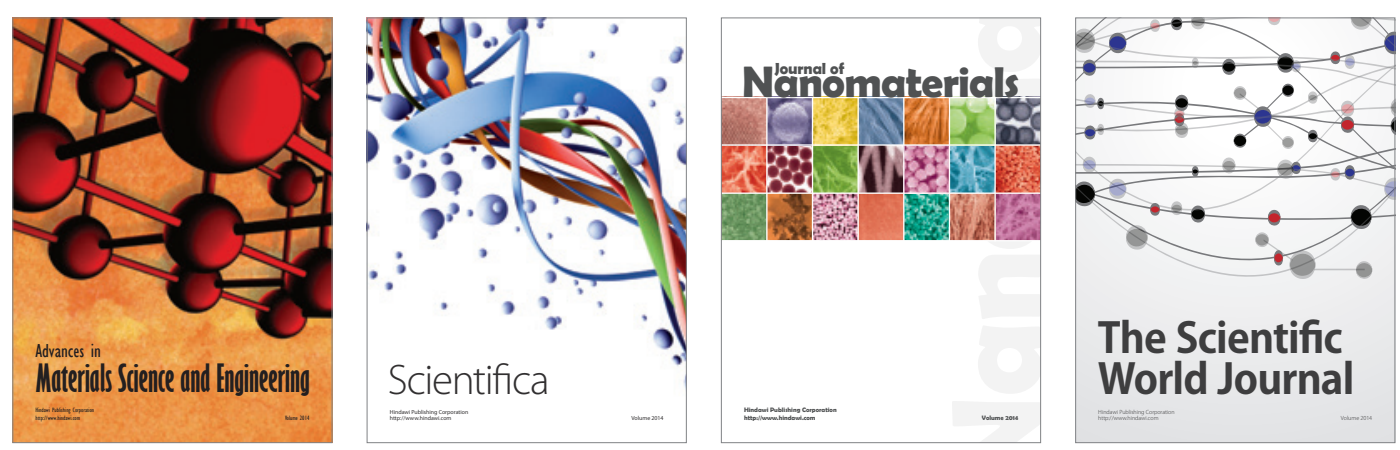

\section{The Scientific World Journal}
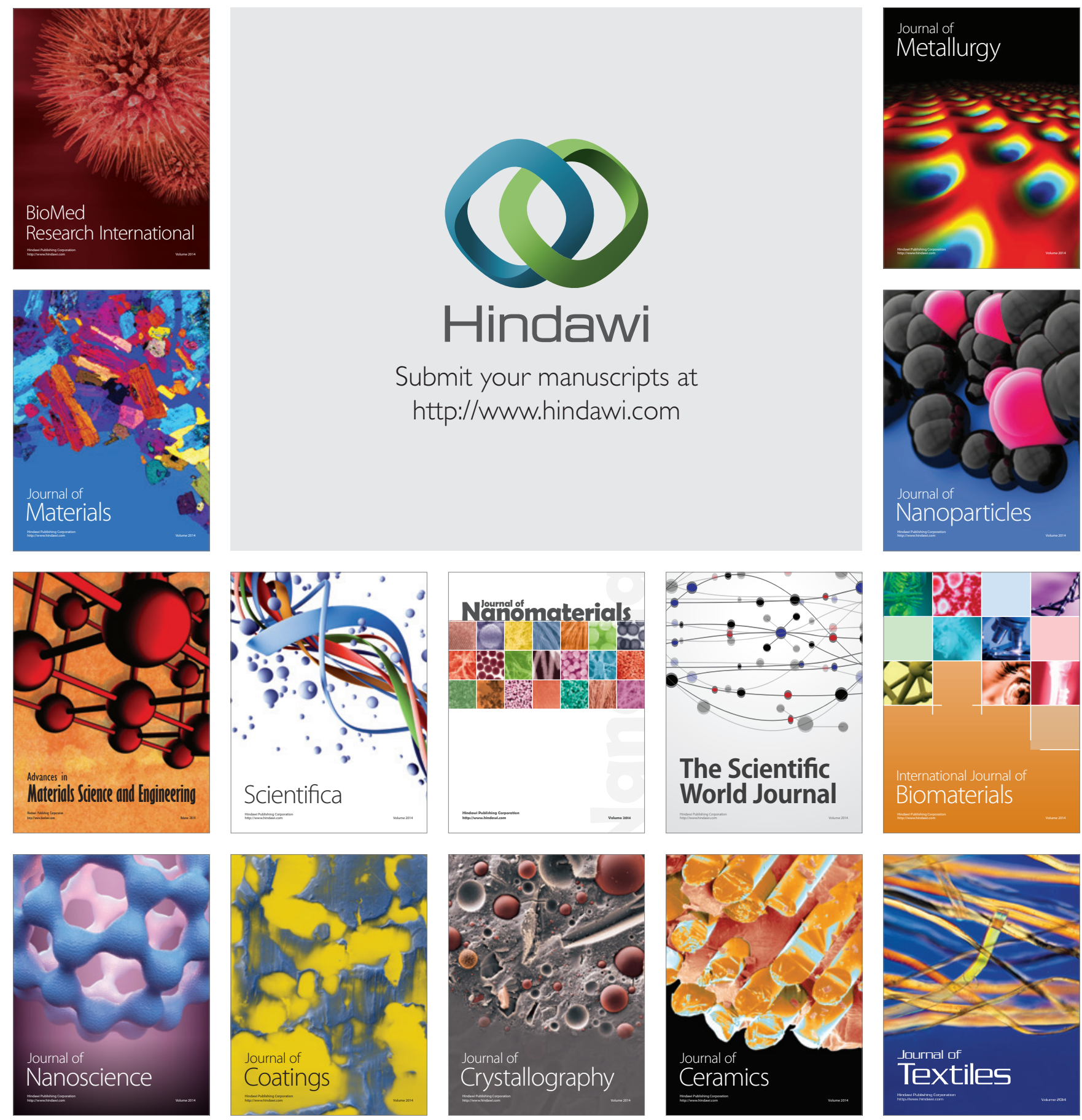